\title{
Prevalência de genótipos e de mutantes pré-core A-1896 do vírus da hepatite B e suas implicações na hepatite crônica, em uma população da Amazônia oriental
}

\author{
Prevalence of hepatitis B virus genotypes and the occurrence of precore mutation A-1896 \\ and to correlate them with the clinical presentation of chronic hepatitis, in a \\ population group of the Eastern Amazon region
}

\author{
Simone Regina Souza da Silva Conde ${ }^{1}$, Lizomar de Jesus Pereira Móia ${ }^{1}$, Maria Silvia Brito \\ Barbosa ${ }^{1}$, Ivanete do Socorro Abarcado Amaral ${ }^{1}$, Esther Castello Branco de Mello Miranda ${ }^{1}$, Manoel \\ do Carmo Pereira Soares'2, Elizabete Maria de Figueiredo Brito², Olglaíze do Socorro Costa Souza², \\ Marialva Tereza de Araújo ${ }^{3}$, Sâmia Demachki ${ }^{3}$, João Renato Pinho Rebello ${ }^{4}$, Michele Gomes \\ Soares Mesquita ${ }^{4}$, Denis Alberto Bertollini ${ }^{4}$ e Ricardo Ishak $^{3}$
}

\begin{abstract}
RESUMO
Ainfecção pelo virus da hepatite B apresenta amplo espectro de manifestações clínicas. Objetivando conhecer os genótipos do HBV mais prevalentes e determinar a ocorrência da mutação pré-core A-1896, em uma população da Amazônia oriental, correlacionando com o diagnóstico clínico, foram selecionados 51 pacientes portadores crônicos de HBsAg e HBV-DNA positivos e divididos em três grupos: grupo $\mathrm{A}$ ( $\mathrm{n}=14$, pacientes assintomáticos); grupo $\mathrm{B}(\mathrm{n}=20$, sintomáticos HBeAg positivos) e grupo $\mathrm{C}$ ( $\mathrm{n}=17$, sintomáticos $\mathrm{HBeAg}$ negativos), sendo usado 0 sequenciador automático ABI modelo 377 para identificação de genótipos e mutantes pré-core. Os resultados evidenciaram o genótipo A como o mais prevalente, $81,8 \%, 89,5 \%$ e 93,7\%, nos grupos A, B e C, respectivamente. A mutação pré-core A-1896 foi encontrada em 11,5\% (3/26) , sendo todos assintomáticos. Concluiu-se que na população estudada o genótipo A foi o mais prevalente e houve baixa ocorrência do mutante pré-core A-1896, ambos não se constituindo fatores agravantes da doença hepática.
\end{abstract}

Palavras-chaves: Hepatite B crônica. Genótipos. Mutação pré-core. Epidemiologia. Clínica.

\begin{abstract}
Hepatitis B virus ( $\mathrm{HBV}$ ) infection presents itself with a variety of clinical manifestations. The present work aims to describe the prevalence of HBV genotypes and the occurrence of precore mutation A-1896 in a population group of the Eastern Amazon region of Brazil and to correlate them with the clinical presentation of chronic HBV infection. 51 HBsAg carriers (HBV-DNA positive) were selected and divided into three groups: A (14 asymptomatic subjects) , B (20 HBeAg positive symptomatic patients) and C (17 HBeAg negative symptomatic patients). Using an automa ed DNA sequencer $\mathrm{ABI}$ model 377 by sequencing for determined of genotypes and precore mutation. The results showed that the genotype A was the most commonly found $(81,1 \%, 89,5 \%$ and $93,7 \%$ in groups A, B and C, respectively) and precore mutation A-1896 was described in 11,5\% (3/26) of group A subjects. Genotype A of HBV was the most prevalent ( 89,1\%) and low occurrence of precore mutation A-1896, both not associate with the worst outcome of the chronic infection of HBV.
\end{abstract}

Key-words: Chronic hepatitis B. Genotypes. Precore mutation. Epidemiology. Clinical.

1. Fundação Santa Casa de Misericórdia do Pará, Belém, PA, 2. Instituto Evandro Chagas, Belém,PA, 3. Universidade Federal do Pará, Belém, PA. 4. Instituto Adolfo Lutz, São Paulo, SP.

Endereço para correspondência: Dra. Simone Regina Souza da Silva Conde. Rua diogo Móia 197/901, Umarizal, 66055-170 Belém, PA.

Tel: 91 9112-8889

e-mail: conde@ libnet.com.br 
A infecção pelo vírus da hepatite B (HBV) apresenta distribuição universal, reconhecendo-se a existência de 350 milhões de portadores crônicos, sendo responsável por um milhão de óbitos por ano ${ }^{11}$. 0 estudo da história natural da hepatite $B$ evidenciou manifestações clínicas variáveis, na dependência de fatores relacionados ao hospedeiro e ao próprio vírus, sendo descritos quadros agudos assintomáticos ou oligossintomáticos ou ictéricos, possibilidade de hepatite fulminante, cronificação e desenvolvimento de portadores inativo, cirrose hepática e hepatocarcinoma ${ }^{518}$.

0 HBV é 0 protótipo da família Hepadnaviridae e em seu genoma composto por DNA de fita dupla incompleta se reconhece quatro principais regiões de transcrição $(\mathrm{ORF})$ : a) 0 gene $\mathrm{P}$ que codifica a polimerase viral; b) 0 gene pré-C/C (core) responsável pela codificação do $\mathrm{HBCAg}$ e de outra proteína não estrutural, 0 HBeAg; c) o gene pré-SI/S2 e S (superfície) codificante do HBsAg e das proteínas conhecidas como Le M, ed) o geneXque através de sua transcrição produz a proteína $\mathrm{X}^{12}$. 0 seqüenciamento da região Sdo genoma do HBV revelou a presença de sete genótipos do $\mathrm{HBV}$, de $\mathrm{A}$ a $\mathrm{G}^{33}{ }^{34}$, os quais possuem uma distribuição geográfica peculiar.

A presença do HBeAg no soro é epidemiologicamente relacionado com a replicatibilidade e contagiosidade do vírus. Porém, em estudos pioneiros Carman et $\mathrm{al}^{7}$ e Okamoto et al ${ }^{35}$ identificaram mutantes que não sintetizavam $0 \mathrm{HBeAg}$, não interferindo, porém, no ciclo replicativo do mesmo, surgindo 0 termo mutação pré-core. A principal causa desta mutação deve-se à substituição da $\mathrm{G}$ (guanina) pela $\mathrm{A}$ (adenina) na posição do nucleotídio (nt) 1896, e mais raramente no nt 1899, modificando 0 códon TGG específico para 0 aminoácido triptofano para um códon de parada precoce TAG, principalmente nos genótipos que possuem a timina ( $\mathrm{T}$ ) no nt 1854, portanto no B, C, D e F, e raro no A genótip $0^{914}$.

Vários estudos tentam correlacionar os diferentes genótipos com a maior ou menor gravidade dos quadros clínicos resultantes da infecção crônica pelo HBV20 43444 , assim como a presença da mutação pré-core. Nesta última situação, os resultados ainda são mais controversos, visto que a prevalência destes mutantes em hepatopatas crônicos é elevada nas regiões do Mediterrâne $0^{4} 14{ }^{38}$, no Oriente Médio $^{23}$ e no leste asiático ${ }^{13} 242832$, porém baixa ao norte europeu, EUA e Brasil ${ }^{229} 39$; e ainda são identificados mutantes em portadores inativos do vírus ${ }^{15236}$.

Sendo a região Amazônica considerada uma área de alta prevalência do HBV e a falta de estudos sobre a prevalência de genótipos e mutantes pré-core nesta população, 0 presente trabalho objetiva conhecer os genótipos mais prevalentes do HBV e a descrição da prevalência de mutação pré-core A- 1896 entre os pacientes portadores de hepatite crônica $B$, em uma população da Amazônia oriental, assim como correlacionar com as características epidemiológicas, clínicas e virológicas.

\section{MATERIAL E MÉTODOS}

População de estudo. Selecionou-se 51 pacientes portadores crônicos do HBsAg ( HBV-DNA positivo) atendidos no Programa de Hepatopatias Crônicas do Hospital da
Fundação Santa Casa de Misericórdia do Pará, localizado na cidade de Belém. Excluíram-se do estudo pacientes com infecção simultânea pelo vírus da hepatite C (HCV), delta (HDV) ou vírus da imunodeficiência humana (HIV), ou os que utilizaram qualquer tipo de tratamento antiviral prévio. 0 total de pacientes selecionados foi divido em três grupos: grupo A formado por pacientes assintomáticos HBeAg positivos e negativos (n: 14); grupo B, por aqueles pacientes sintomáticos HBeAg positivos ( $\mathrm{n}$ : 20); e grupo C, por pacientes sintomáticos HBeAg negativos e anti-HBe positivos (n: 17). Estes foram submetidos a exames clínicos, laboratoriais, sorológicos, ultra-sonográficos, endoscópicos e, quando indicado, a biópsias hepáticas para estadiamento. Após a identificação destes grupos, procedeu-se a genotipagem de todos os espécimes e 0 seqüenciamento da região pré-core nos portadores do HBV com HBeAg negativo, tanto assintomáticos quanto sintomáticos.

Testes sorológicos e de pesquisa do HBV-DNA. Para os exames sorológicos das hepatites B, C e D foram utilizados EIE, tipo ELISA, com kits comerciais. Todos os soros foram examinados para a presença de HBsAg (Organon Teknika ${ }^{\circledR}$, Holanda), anti$\mathrm{HBc}$ (Organon Teknika ${ }^{\circledR}$, Holanda), anti-HBs (Abbott $\AA$, EUA) e anti-HCV ( Ortho Clinical Diagnostics $®$, Alemanha). Nas amostras positivas para $0 \mathrm{HBsAg}$ foi efetuada a pesquisa do $\mathrm{HBeAg}$, anti$\mathrm{HBe}$, anti-HBc IgM a anti-HD (Organon Teknika ${ }^{\circledR}$, Holanda).

0 HBV-DNA foi pesquisado do modo qualitativo e quantitativo utilizando-se kits comerciais do laboratório Roche ${ }^{\circledR}$ (AMPLICOR HBV MONITOR ${ }^{\mathrm{TM}}$ ), que utiliza a PCR para a amplificação e hibridização do DNA.

Genotipagem do HBV. Para detecção da região $S$ do HBV-DNA no soro por PCR, foi empregada a técnica de extração desenvolvida por Kaneko et $\mathrm{a}^{19}$ e por Kwok \& Higuchi ${ }^{25}$ com poucas modificações. A extração do DNA viral se procedeu pelo $\mathrm{NaOH}$ e os primers utilizados nas $\mathrm{PCR}$ foram 0 FHBS1 (GAG TCT AGA CTC GTG GTG GAC TTC) , 0 RHBS1, para a primeira reação e o FHBS2 (CGT GGT GGA CTT CTC TCA ATT TTC) e RHBS2 (GCC ARG AGA AAC GGR CTG AGG CCC) para a segunda.

Aanálise do produto de PCR se procedeu com a aplicação em gel de agarose, submetido à corrente elétrica de $150 \mathrm{~V}$ por 35 minutos e revelada a reação com a utilização de uma fonte de ultravioleta (UV). 0 produto foi fotografado com máquina tipo Polaroid. As amostras foram consideradas positivas quando apresentaram uma banda de 450pb, quando comparadas ao padrão. As amostras positivas foram seqüenciadas por PCR, derivada da metodologia de Sanger et $\mathrm{al}^{37}$ utilizando-se didesoxinucleotídeos ( dNIPs) contendo marcadores fluorescentes, conforme 0 kit ABI Prism ${ }^{\mathrm{R}}$ BigDye $^{\mathrm{TM}}$ Terminator (PE Applied Biosystems).

A análise dos genótipos foi realizada por meio da comparação das seqüências obtidas com as já conhecidas dos diferentes genótipos de HBV. Para esta análise foram utilizados os programas EditSeq e Megalign do pacote DNAstar ( Lasergene Inc, USA).

Seqüenciamento da região Pré-core do HBV. 0 seqüenciamento da região pré-core do HBV foi efetuado nas 
amostras HBeAg negativas dos grupos A e C. A extração do DNA viral se procedeu com a utilização da solução de isotiocianato de guanidina (solução GT) e os primers para a primeira e segunda PCR foram o EP1.1 (TCA TGG AGA CCA CCG TGA AC) e EP1.2 (GGAAAG AAG TCA GAA GGCAA) e o EP2.1 (CAT AAG AGG ACT CTT GGA CT) e EP2.2 (GGC AAA AAA GAG AGT AAC TC), respectivamente. Após a colocação do produto em gel de agarose a 1\% e submetido a corrente elétrica, revelou-se a reação com a utilização de uma fonte de ultravioleta ( UV) , fotografando com máquina tipo Polaroid, sendo consideradas positivas quando apresentaram uma banda de 300pb.

Os produtos das reações de amplificação foram aplicados em gel de policrilamida e submetidos à eletroforese no sequenciador automático, modelo ABI Prism ${ }^{\mathrm{TM}} 377$ DNA Sequencer (Perkin Elmer). As seqüências da região pré-core foram alinhadas a uma seqüência conhecida da mesma região, livre de mutações, utilizando-se para isto os programas EditSeq e Megalign do pacote DNAstar ( Lasergene Inc, USA). Posteriormente, analisou-se os pontos das sequêencias que foram marcados por serem diferentes da seqüência consenso, visando o encontro de mutações A-1896 e A-1899, além de outras citadas em publicações científicas.

Para a análise estatística foram utilizados os programas EPIINF0 6.04 b e Biostat 2.03. Utilizaram-se testes estatísticos paramétricos da ANOVA de um e de dois critérios e os nãoparamétricos de Kruskal-Wallis e de Kolmogorov-Smirnov, nos casos de análise de variância de mais de duas amostras. Para duas amostras independentes, os testes não paramétricos empregados foram 0 qui-quadrado e 0 teste exato de Fisher. Estabeleceu-se em 0,05 (5\%) 0 nível de rejeição da hipótese de nulidade (valor de $\mathrm{p} \leq 0,05$ ).

0 presente trabalho foi aprovada pelo Comitê de Ética Médica da Fundação Santa Casa de Misericórdia do Pará, e os pacientes selecionados foram conscientizados sobre os objetivos do estudo e assinaram um Termo de Consentimento Livre e Esclarecido, permitindo assim a realização da investigação.

\section{RESULTAD0S}

Os três grupos formados se caracterizaram por um predomínio total do sexo masculino, cada um dos quais apresentando apenas um paciente do sexo feminino. A média das idades foram de 32,4 \pm 12,3 anos (variação de 10-60 anos) para 0 grupo A, 41,6 \pm 26,3 anos (variação de 1-84 anos)

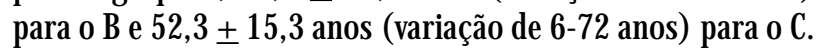
A diferença destas médias se mostrou estatisticamente significante entre os grupos Ae C, com valor de pigual a 0,028.

As complicações clínicas em decorrência da doença hepática, ocorridas em 7/20 (35\%) pacientes do grupo B e em 9/17 (53\%) do grupo C, e a letalidade de 15\% (3/20) dos pacientes do grupo B e 35,2\% (6/17) do C não apresentaram diferenças estatísticas entre si.

Nas dosagens de AST, ALT, bilirrubina total, FA, GGT e globulinas, o grupo A apresentou menores valores do que no grupo $B(p: 0,005)$ e C (p: 0,001). As médias das dosagens de albumina e atividade protrombínica foram menores nos grupos B e C em relação ao A (Tabela 1) e a diferença mostrou-se estatisticamente significante ( p: 0,001 e p: 0,007, respectivamente).

Tabela 1 - Exames laboratoriais complementares dos pacientes dos grupos $\mathrm{A}, \mathrm{BeC}$.

\begin{tabular}{|c|c|c|c|c|}
\hline & $\begin{array}{c}\text { Grupo A } \\
\text { média } \pm \text { DP }\end{array}$ & $\begin{array}{c}\text { Grupo B } \\
\text { média } \pm \text { DP }\end{array}$ & $\begin{array}{c}\text { Grupo C } \\
\text { média } \pm \mathrm{DP}\end{array}$ & \\
\hline ALT & 33,2 & 135,5 & 115,1 & p: $0,002^{*}$ \\
\hline$(08-54 \mathrm{iu} / \mathrm{l})$ & $\pm 22,0$ & $\pm 223,7$ & $\pm 137,9$ & \\
\hline Bilirrubina total & 0,7 & 3,1 & 3,0 & $\mathrm{p}: 0,041^{*}$ \\
\hline$(0,4-1,4 \mathrm{mg} / \mathrm{dl})$ & $\pm 0,3$ & $\pm 3,8$ & $\pm 3,0$ & \\
\hline GGT & 34,3 & 122,0 & 98,6 & $\mathrm{p}: 0,020^{*}$ \\
\hline (08-63 IU/L) & $\pm 28,9$ & $\pm 220,1$ & $\pm 73,9$ & \\
\hline Fosfatase alcalina & 61,1 & 181,0 & 155,3 & p: $0,001^{*}$ \\
\hline$(36-55 \mathrm{~g} / \mathrm{dl})$ & $\pm 30,6$ & $\pm 142,5$ & $\pm 82,3$ & \\
\hline Albumina & 4,7 & 3,2 & 3,6 & p: $0,001^{*}$ \\
\hline$(3,5-5,5 \mathrm{~g} / \mathrm{dl})$ & $\pm 0,6$ & $\pm 1,0$ & $\pm 1,1$ & \\
\hline$\overline{\mathrm{AP}}$ & 90,8 & 67,9 & 53,1 & $\mathrm{p}: 0,007^{*}$ \\
\hline$(>70 \%)$ & $\pm 14,6$ & $\pm 29,5$ & $\pm 24,8$ & \\
\hline
\end{tabular}

DP: desvio padrão. ( ) : valores normais e unidades de referência. ns: não significante ( $p$ $>0,05)$. * significância estatística entre os grupos Ae B e entre $\mathrm{Ae} C$, porém não entre os grupos B e C.

Com relação às cargas virais, 0 grupo $B$ apresentou níveis superiores às do A e C, com valor de p igual a 0,004 (Figura 1). Ressalta-se que o único indivíduo HBeAg positivo do grupo A possuía carga viral de $7,332\left(\log _{10}\right)$, muito acima dos demais membros deste mesmo grupo.

0 diagnóstico final dos pacientes do grupo $\mathrm{B}$ e $\mathrm{C}$ encontram-se expostos na Tabela 2. Não foi possível demonstrar diferença estatística entre eles.

Genotipagem do HBV. Das 51 amostras de soro de pacientes processadas para genotipagem, conseguiu-se êxito em 11 (79\%) do grupo A, 19 (95\%) do grupo B e 17 (94\%) do grupo C. As amostras que não se conseguiu efetuar a

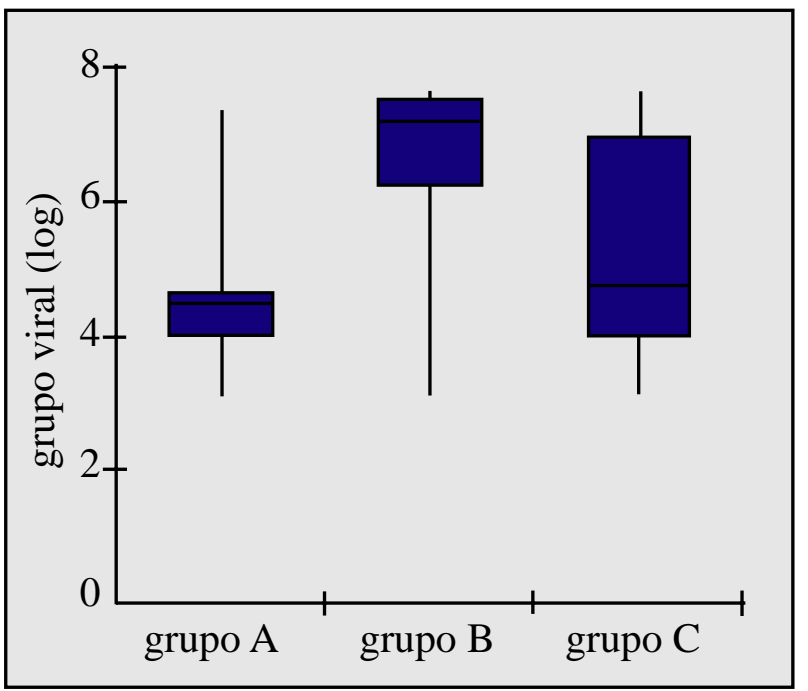

Figura 1 - Mediana e quartis das cargas virais $\left(\right.$ em $\log _{10}$ ) do HBV dos grupos A, B e C. 
Tabela 2 - Diagnóstico final (clínico e/ou histopatológico) dos pacientes dos grupos B eC.

\begin{tabular}{lrrrrrr}
\hline & \multicolumn{2}{c}{ Grupo B (20) } & & \multicolumn{2}{c}{ Grupo C (17) } \\
\cline { 2 - 3 } Diagnóstico & $\mathrm{n}^{\mathbf{0}}$ & $\%$ & & $\mathrm{n}$ & $\%$ & \\
\hline Hepatite crônica & 8 & 40,0 & & 5 & 29,5 & $\mathrm{~ns}$ \\
Cirrose hepática & 9 & 45,0 & & 7 & 41,0 & $\mathrm{~ns}$ \\
Hepatocarcinoma & 3 & 15,0 & & 5 & 29,5 & $\mathrm{~ns}$ \\
\hline
\end{tabular}

ns: não significante $(p>0,05)$

extração do ácido nucléico apresentaram carga viral baixa, inferior a 2.500 cópias/mL ( Figura 2).

A genotipagem das 46 amostras positivas revelou a presença do genótipo A na grande maioria dos pacientes, 89,1\% (41/46), seguido dos genótipos F em 8,7\% (4/46) e D em 2,2\% (1/46). A distribuição dos genótipos encontrados nos grupos estudados está resumida na Tabela 3.

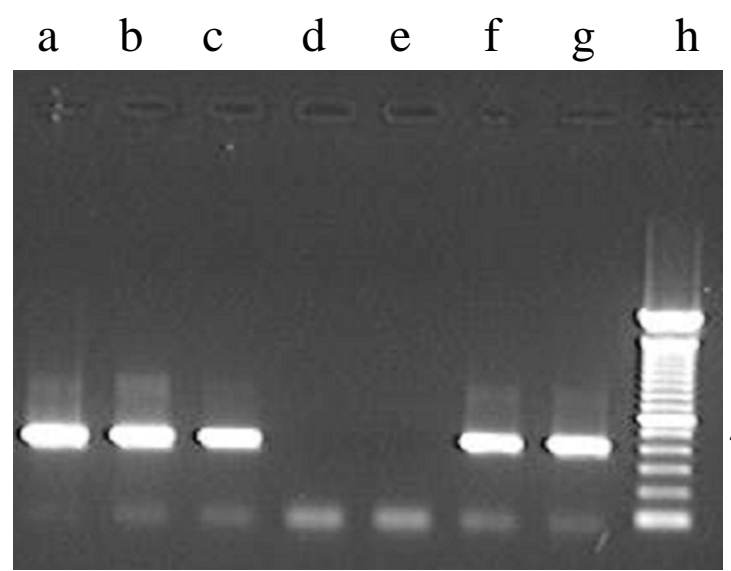

$450 \mathrm{pb}$

Figura 2 - Detecção por eletroforese em gel de agarose a $1 \%$ do produto de amplificação da região S do HBV (450 pb). Lanes a, b, c, f e g: amostras positivas; lane d: controle negativo; lane e: amostra negativa, lane h: padrão.

Tabela 3 - Distribuição dos genótipos do HBVnos grupos A, B e C.

\begin{tabular}{llrrrrrr}
\hline & & \multicolumn{7}{c}{ Genótipos } \\
\cline { 3 - 8 } Grupos & $\mathrm{N}$ & $\mathrm{A}$ & $\%$ & $\mathrm{D}$ & $\%$ & $\mathrm{~F}$ & $\%$ \\
\hline A & 11 & 9 & 81,8 & 1 & 9,1 & 1 & 9,1 \\
B & 19 & 17 & 89,5 & 0 & - & 2 & 10,5 \\
C & 16 & 15 & 93,7 & 0 & - & 1 & 6,3 \\
\hline Total & & 41 & 89,1 & 1 & 2,2 & 4 & 8,7
\end{tabular}

Quanto à procedência destes pacientes (Figura 3), observou-se que a maior parte dos pacientes com genótipo A, 68,3\% (28/41), procediam da região metropolitana de Belém e da região sudeste do Pará. 0 paciente com genótipo D procedeu de Belém, assim como dois outros com genótipo F. Deste último genótipo, um terceiro paciente era oriundo de Cametá (Baixo Tocantins) e o quarto, de Vizeu, nordeste do Estado do Pará.

As características demográficas dos pacientes ( Tabela 4) não mostraram diferenças estatísticas, quando distribuídas de acordo com 0 genótipo encontrado.

A presença do HBeAg entre os indivíduos portadores do genótipo A foi de 43,9\% (18/41), taxa semelhante a encontrada nos do genótipo não $\mathrm{A}$.

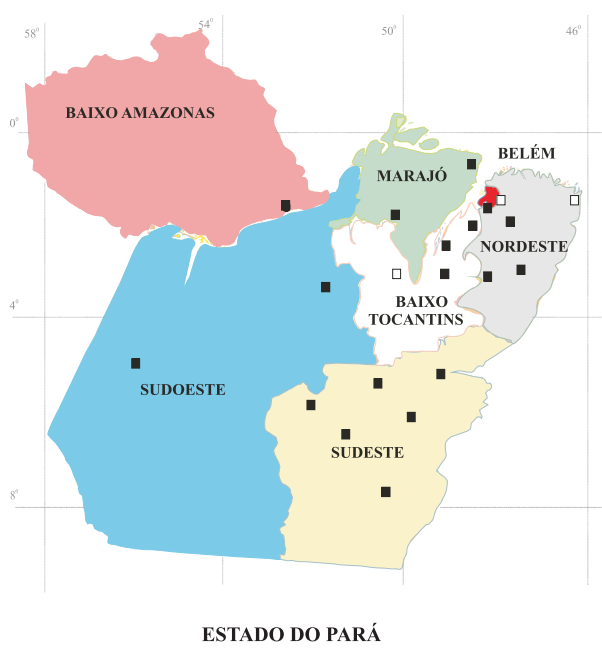

\begin{tabular}{|lcc|}
\hline Procedência & 『 Genótipo A (41) & $\square$ Genótipo não A (05) \\
Belém & 20 & 3 \\
Nordeste & 3 & 1 \\
Marajó & 2 & 0 \\
Baixo Tocantins & 3 & 1 \\
Sudeste & 9 & 0 \\
Sudoeste & 3 & 0 \\
Baixo Amazonas & 1 & 0 \\
\hline
\end{tabular}

Figura 3 - Procedência dos pacientes com genótipo A e não A do HBV.

Tabela 4 - Características demográficas dos pacientes com genótipos Ae não $\mathrm{A}(\mathrm{DeF})$.

\begin{tabular}{lccc}
\hline Características & $\begin{array}{c}\text { Genótipo A } \\
(41)\end{array}$ & $\begin{array}{c}\text { Genótipo não A } \\
\text { (D: 1 e F: 4) }\end{array}$ & \\
\hline Sexo M/F & $39 / 2$ & $5 / 0$ & $\mathrm{~ns}$ \\
Idade (anos) média \pm DP & $44+22,6$ & $33+11,6$ & $\mathrm{~ns}$ \\
Cor (\%) & & & $\mathrm{ns}$ \\
$\quad$ branca & 13,5 & 25,0 & \\
negra & 5,4 & 0 & \\
$\quad$ parda & 78,4 & 75,0 & \\
$\quad$ amarela & 2,7 & 0 & \\
ns: não significante $(\mathrm{p}>0,05)$ & & &
\end{tabular}

A média da carga viral ( $\mathrm{em} \log _{10}$ ) das 41 amostras com genótipo A, 7.008 cópias/mL, e a dos cinco pacientes com genótipos não A, 6.716 cópias/mL não apresentaram diferença estatística significante ( Figura 4).

0 caso de genótipo $D$ encontrava-se na condição de assintomático. Nos quatro indivíduos com genótipo F, cada grupo de diagnóstico, assintomático, hepatite crônica, cirrose

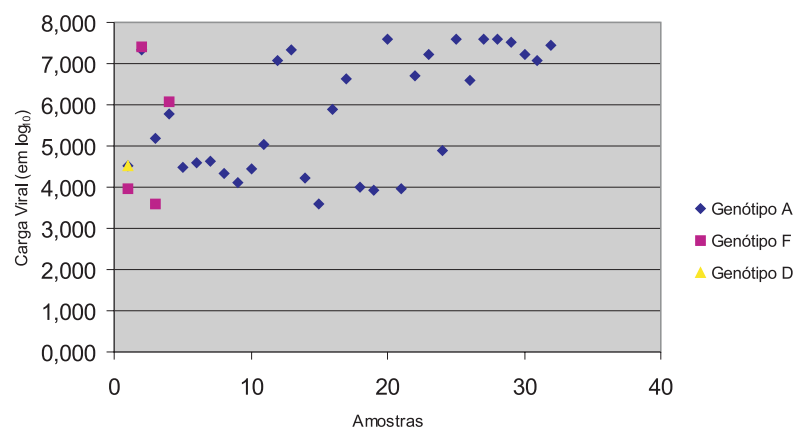

Figura 4 - Distribuição da carga viral $\left(\right.$ em $\left.\log _{10}\right)$ das amostras de genótipos A, F e D. 
hepática e hepatocarcinoma, recebeu um representante. Os representantes do genótipo A eram em 22\% (9/41) assintomáticos, em 26,8\% (11/41) portadores de hepatite crônica, 36,6\% (15/41) portadores de cirrose hepática e, finalmente, 14,6\% (6/41) portadores de CHC (Tabela 5).

Tabela 5 - Presença do HBeAg, dosagem da carga viral e o diagnóstico dos casos com genótipo Ae dos genótipos não A(D e F).

\begin{tabular}{lccc}
\hline & $\begin{array}{c}\text { Genótipo A } \\
(41)\end{array}$ & $\begin{array}{c}\text { Genótipo diferente de A } \\
\text { (D: } 1 \text { e F: } 4)\end{array}$ \\
\hline HBeAg positivo & 18 & 2 & $\mathrm{~ns}$ \\
Média da carga viral & 7,008 & 6,716 & $\mathrm{~ns}$ \\
$\left(\log _{10}\right) \pm \mathrm{DP}($ cópias $/ \mathrm{mL})$ & $\pm 7,156$ & $\pm 7,040$ & \\
Diagnóstico & & & $\mathrm{ns}$ \\
$\quad$ assintomático & 9 & 2 & \\
$\quad$ hepatite crônica & 12 & 1 & \\
$\quad$ cirrose hepática & 14 & 1 & \\
$\quad$ hepatocarcinoma & 6 & 1 & \\
ns: não significante $(\mathrm{p}>0,05)$ & &
\end{tabular}

Mutação pré-core A-1896/ A-1899 do HBV. No total de amostras testadas, 11,5\% (3/26) mostraram-se positivas para as mutações pesquisadas ( Tabela 6) . No grupo A ( Figura 5) , a presença de mutação pré-core foi encontrada em três (25\%) amostras, sendo uma do tipo A-1896, uma do tipo A1899 e uma do tipo combinado A-1896 com A-1899. No grupo C, não foi possível evidenciar tal mutação. Ainda assim, 0 resultado não mostrou diferença estatística entre os dois grupos analisados (valor de p igual a 1).

Tabela 6 - Prevalência de mutação pré-core A-1896 e A-1899 nos pacientes dos grupos Ae C HBeAg negativos.

\begin{tabular}{lccc}
\hline & Grupo A(12) & Grupo C(14) & Total \\
\hline Positivo (n) $\%$ & (3) $25,0^{*}$ & 0 & (3) 11,5 \\
Negativo (n) $\%$ & (9) 75,0 & (14) 100,0 & (23) 88,5 \\
Total & (12) 100,0 & (14) 100,0 & (26) 100,0
\end{tabular}

* Um caso de mutação A-1896, um de A-1899 e um caso de associação da A-1896 e A1899.

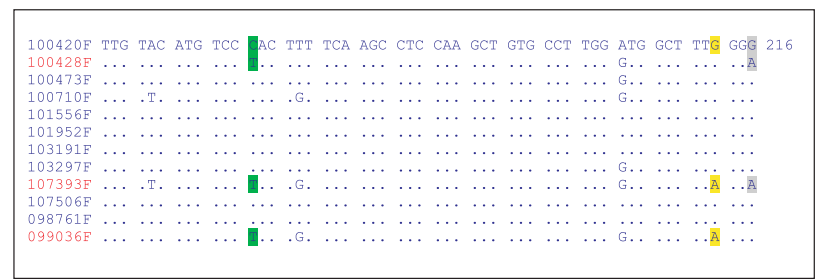

Figura 5 - Seqüências nucleotídicas da região pré-core do HBV de 12 amostras dos pacientes do grupo A. (-): nucleotídeos. (-) : nt 1854. (-): nt 1896. nt(-): nt 1899. • : cepa selvagem. • : cepa com mutação pré-core A-1899/ A-1896 e 1899/ A-1896.

A presença do mutante pré-core foi observada em dois casos de genótipo A, nos quais também a mutação T-1858 estava presente, e em um caso de genótipo D. Contudo, outras mutações também foram encontradas, entre as quais destacam-se a T-1762 e a A-1764 (Tabela 7).

Os três indivíduos portadores do HBV mutante pré-core A-1896/ A-1899 eram do sexo masculino, procedentes da região metropolitana de Belém e com idades de 22, 34 e 29
Tabela 7 - Relação de tipos de mutações pré-core encontradas nos grupos AeC.

\begin{tabular}{|c|c|c|c|c|c|c|}
\hline \multirow[b]{2}{*}{ Tipo de mutação } & \multicolumn{2}{|c|}{ Grupo A (12) } & \multicolumn{2}{|c|}{ Grupo C(15) } & \multicolumn{2}{|c|}{ Total (27) } \\
\hline & $\overline{n^{0}}$ & $\%$ & $\overline{n^{0}}$ & $\%$ & $\overline{\mathrm{n}^{0}}$ & $\%$ \\
\hline T-1858, A-1896 & 1 & 8,3 & 0 & & 1 & 3,7 \\
\hline T-1762, A-1764, T-1858, A-1899 & 1 & 8,3 & 0 & - & 1 & 3,7 \\
\hline T-1762, A-1764, T-1858, A-1896, A-1899 & 1 & 8,3 & 0 & - & 1 & 3,7 \\
\hline T-1762, A-1764 & 5 & 41,8 & 8 & 53,2 & 13 & 48,2 \\
\hline C-1814 & 1 & 8,3 & 1 & 6,7 & 2 & 7,4 \\
\hline T-1762, A-1764, C-1814 & 2 & 16,7 & 2 & 13,3 & 4 & 14,8 \\
\hline T-1762 & 0 & - & 1 & 6,7 & 1 & 3,7 \\
\hline T-1762, A-1764, T-1858 & 0 & - & 1 & 6,7 & 1 & 3,7 \\
\hline Sem mutações & 1 & 8,3 & 1 & 6,7 & 2 & 7,4 \\
\hline
\end{tabular}

anos e assintomáticos. As médias das cargas virais $\left(\mathrm{em} \log _{10}\right)$ dos três indivíduos 4,735 cópias $/ \mathrm{mL}$, e a do restante dos 23 sem mutação pré-core A-1896/A-1899, 4,922 cópias/mL, não apresentaram diferenças estatisticamente significantes entre si, com p: 0,399.

\section{DISCUSSÃO}

Na caracterização dos grupos estudados, observou-se um predomínio do sexo masculino e da faixa etária adulta nos três. Contudo, o grupo A possuía média de idade inferior aos demais, com significância estatística em relação ao grupo C. Este dado se assemelha com os trabalhos de Mangia et $\mathrm{al}^{29} \mathrm{e}$ Nitsuma et $\mathrm{al}^{32}$, em que os pacientes portadores assintomáticos do $\mathrm{HBV}$ eram mais jovens em relação aos doentes crônicos HBeAg negativos. 0 grupo B, composto de pacientes HBeAg positivos, foi o que

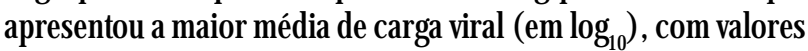
significativamente maiores do que os encontrados nos grupos A e C (p: 0,004). Chu et $\mathrm{a}^{10}$ ao analisarem 79 pacientes com hepatite crônica $B$, todos comprovados histologicamente, encontraram níveis séricos do HBV-DNA por dot-blot de 944 $\mathrm{pg} / \mathrm{mL}$ nos HBeAg positivos, sendo maior do que os $58 \mathrm{pg} / \mathrm{mL}$ encontrados nos anti-HBe positivos. A média de idade e a carga viral se mostraram inversamente proporcionais no grupo $B$ e foi menor do que nos pacientes do grupo $\mathrm{C}$.

A genotipagem das amostras do HBV mostrou que $89,1 \%$ pertenciam ao genótipo A, 8,7\% ao Fe 2,2\% ao D. Os estudos de genotipagem descrevem uma ocorrência variada de genótipos de acordo com a situação geográfica examinada.

0 genótipo A é o mais prevalente no norte europeu, na África ( seguido em menor proporção pelo D e E) , EUA e em descrições de prevalência de populações urbanas com alto fluxo migratório de países da América do Sul ${ }^{27} 30333439$.

A genotipagem das amostras provenientes de cinco países da América Central (Nicarágua, Costa Rica, Guatemala, El Salvador e Honduras) detectou a presença do genótipo $\mathrm{F}$ em $79 \%$ das amostras, além de 14\% do genótipo A, 6\% do D e 1\% do $\mathrm{C} 2$, sugerindo ser $0 \mathrm{~F} 0$ genótipo nativo da região ${ }^{2}$. Moraes et $\mathrm{a}^{31}$ demonstrando uma técnica de PCR específica para genotipar amostras de HBV, identificou em 54 espécimes provenientes de Manaus (AM) e Macapá ( $\mathrm{AP}$ ) 69\% de genótipo 
A, $31 \%$ de $D$ e $7,4 \%$ de $F$, e sugeriu que em outros estudos houve uma superestimação do genótipo $\mathrm{F}$. Em trabalho recente, Bertolini et $\mathrm{al}^{6}$ demonstraram em três comunidades indígenas da região Amazônica o predomínio total do genótipo $\mathrm{F}$ e em uma quarta $100 \%$ dos pesquisados pertenciam ao genótipo $\mathrm{A}$, sendo que esta comunidade mantinha um alto grau de aculturação e contato com populações tri-híbridas.

0 genótipo D é o predominante no sul da Europa e parte do Oriente Médio. Ao norte e sudoeste do continente asiático se destacam os genótipos B e C ${ }^{27} 33$. Trabalhos realizados com aborígenes australianos evidenciaram a presença do genótipo $\mathrm{C}^{1}$.

Ao descreverem 0 genótipo $\mathrm{G}$, em pacientes norteamericanos e franceses cronicamente infectados pelo HBV, Stuyver et $\mathrm{al}^{41}$ observaram que 0 genótipo $\mathrm{A}$ também era 0 mais prevalente, com $54 \%$ do total de casos, seguido do D (19\%), C (12\%), G (11\%), B (3\%) e E (1\%). Neste estudo, o genótipo $\mathrm{F}$ não foi encontrado.

Como se pode observar, a extensão geográfica do Brasil, as diferenças regionais de cultura, diferenças de poder aquisitivo, composição étnica, padrões de conforto, educação, dentre outros, conseguem influenciar na grande variabilidade não só da prevalência do $\mathrm{HBV}^{40}$, como também de seus genótipos de acordo com a classificação atual no seqüenciamento da região $S^{63139}$.

Comunidades epidemiologicamente fechadas conseguem ter introduzido um genótipo e mantê-lo como o único circulante, enquanto que aqueles grupos em que acontece a circulação de vários genótipos, as freqüências de ocorrência são variadas e não existe, aparentemente, algum fator biológico do vírus que favoreça o predomínio de um ou outro genótipo. A maior influência, provavelmente, se dá pelos fatores associados à transmissão do HBV.

No presente trabalho, não foi possível mostrar a influência de possíveis variações genotípicas com as manifestações clínicas e a gravidade da doença hepática crônica pelo HBV, como já proposto em outros estudos 20214345 .

A procura da mutação pré-core A-1896 e/ou A-1899 nos pacientes HBeAg negativos, grupos $\mathrm{A}$ e $\mathrm{C}$, mostrou que nos 12 seqüenciamentos dos pacientes assintomáticos, três (25\%) possuíam esta mutação, enquanto que em 14 pacientes do grupo sintomático HBeAg negativo, em nenhum foi possível mostrar a mutação. A baixa prevalência desta mutação, $11,5 \%$ (3/26) já era esperada devido a alta prevalência do genótipo A nos grupos estudados.

A mutação pré-core A-1896 em pacientes assintomáticos HBeAg negativos foi descrita por diversos autores $5^{1523232} \mathrm{em}$ uma proporção extremamente variável, de 17, 6\% a 57,2\%, de acordo com a região estudada. Nos locais onde predominam os genótipos B, D ou C, nos pacientes hepatopatas crônicos HBeAg negativos, a mutação pré-core é encontrada em 35\% a 100\% dos $\operatorname{casos}^{1416233846}$, enquanto nos países de maior prevalência do genótipo A, a mutação A-1896 se situa entre 28,5\% a 45,2\%, encontrada principalmente em pacientes com genótipos diferentes do A, nestas populaçõe ${ }^{2939} 45$.

A presença da mutação mesmo em uma freqüência baixa era esperada no grupo C. Por outro lado, a diferença entre os grupos A e C não foi estatisticamente significante, denotando não ser este um fator influenciador na evolução clínica dos pacientes em questão.

No presente trabalho, outras mutações nas regiões promotoras do core e pré-core também foram identificadas. Merecem destaque as mutações T-1762 e A-1764, as quais foram encontradas em $76,9 \%$ dos casos, incluindo os três grupos. A presença dessas mutações foi descrita por Takahashi et $\mathrm{al}^{4243}$ e Karasawa et $\mathrm{al}^{22}$, os quais associaram a combinação das mesmas com a mutação A-1896 e descreveram a possibilidade das mutações influenciarem na evolução clínica dos pacientes infectados pelo HBV.

Estudos futuros com casuísticas maiores deverão ser efetuados para se buscar uma análise mais abrangente sobre a influência dos genótipos e mutação pré-core do HBV na evolução clínica dos pacientes cronicamente infectados, na Amazônia oriental, assim como o significado da presença das mutações promotora do core, T-1762 e A-1764.

\section{REFERÊNCIAS BIBLIOGRÁFICAS}

1. Alestig E, Hannoun C, Horal P, Lindh M. Hepatitis B virus genotypes in Mongols and Australian Aborigines. Archives of Virology 146: 2321-2329, 2001.

2. Arauz-Ruiz P, Norder H, Visoná KA, Magnius LO Molecular epidemiology of hepatitis B virus in Central America reflected in the genetic variability of small s gene. The Journal of Infectious Diseases 176: 851-858, 1997.

3. Ayres M, Ayres Júnior M, Ayres DL, Santos AS. BioEstat 2.0: aplicações estatísticas nas áreas de ciências biológicas e médicas. Belém: Sociedade Civil Mamirauá. Conselho Nacional de Desenvolvimento Científico e Tecnológico. Brasília, 2000.

4. Barbera C, Calvo P, Coscia A, Perugini L, Dastoli G, Randone A, Bonino F, Brunetto M. Precore mutant hepatitis B virus and outcome of chronic infection and hepatitis in hepatitis B e antigen-positive children. Pediatric Research 36: 347-350, 1994.

5. Beasley RP, Lin CC, Hwang LL, Chien CS. Hepatocellular carcinoma and hepatitis B. A prospective study of 22.707 men in Taiwan. The Lancet 21: 1129-1133, 1981.

6. Bertolini DA, Moreira RC, Soares M, Bensabath G, Lemos MF, Mello IMVGC, Pinho JRR. Genotyping of hepatitis B virus in indigenous populations from Amazon region, Brazil. Reviews \& Research 5 (supl 1): 101, 2000.

7. Carman WF, Hadziyannis S, McGarvey MJ, Jacyna MR, Karayiannis P, Makris A, Thomas HC. Mutation preventing formation of hepatitis B e antigen in patients with chronic hepatitis B infection. Lancet 2:588-591, 1989.

8. Castro LD, Niel C, Gomes SA. Low frequency of mutations in the core promoter and precore regions of hepatitis B virus in anti-HBe positive Brazilian carriers. BMC Microbiology 1: 10, 2001.

9. Chan HLY, Hussain M, Lok ASF. Different hepatitis B virus genotypes are associated with different mutations in the core promoter and precore regions during hepatitis B e antigen seroconversion. Hepatology 29: 976-984, 1999.

10. Chu CM, Karayiannis P, Fowler MJF, Monjardino J, Liaw YF, Thomas HC. Natural history of chronic hepatitis B virus infection in Taiwan: studies os hepatitis B virus DNA in serum. Hepatology 5: 431-434, 1985.

11. Davey S. State of the world's vaccines and immunization. World Health Organization, Geneva. p.76-82, 1996.

12. Don G. Hepadnaviridae and their replication. In: Knipe DM, Howley PM( eds) Fields Virology. Lippincott-Ravew, Philadelphia. p.2701-2738, 1996.

13. Ehata T, Chung WL, Omata M. Mutations of hepatitis B virus liver disease. Gastroenterology Japonica 28 ( sup 4) :7-11, 1993.

14. Frias FR, Buti M, Jardi R, Cotrina M, Viladomiu L, Esteban R, Guardia J. Hepatitis $B$ virus infection: precore mutants and its relation to viral genotypes and core mutations. Hepatology 22: 1641-1647, 1995. 
15. Fujiwara K, Yokosuka 0, Ehata T, Chuang WL, Imezeki F, Saisho H, Omata M. The two different states of hepatitis $B$ virus DNA in asymptomatic carriers $\mathrm{HBe}$-antigen-positive versus anti-HBe-positive asymptomatic carriers. Digestive Diseases and Sciences 43: 368-376, 1998.

16. Hamasaki K, Nakata K, Nagayama Y, Ohtsuru A, Daikoku M, Taniguchi K, Tsutsumi T, Sato Y, Kato Y, Nagataki S. Changes in the prevalence of HBeAgnegative mutant hepatitis $B$ virus during the course of chronic hepatitis $B$. Hepatology 20: 8-14, 1994.

17. Hasegawa $\mathrm{K}$, Huang J, Wands JR, Obata H, Liang TJ. Association of hepatitis B viral precore mutations with fulminat hepatitis B in Japan. Virology 185: 460-463, 1991.

18. Hoofnagle JH, Seeff LB. Natural history of chronic type B hepatitis. In: Popper H, Schaffner F (eds) Progress in Liver Diseases. Grune and Stratton, New York. p. 469-479, 1982.

19. Kaneko S, Feinstone SM, Miller RH. Rapid and sensitive method for the detection of serum hepatitis B virus DNA using polymerase chain reaction technique. Journal of Clinical Microbiology 27: 1930-1933, 1989.

20. Kao JH, Chen PJ, Lai MY, Chen DS. Hepatitis B genotypes correlate with clinical outcomes in patients with chronic hepatitis B. Gastroenterology 118: 554-559, 2000

21. Kao JH, Chen PJ, Lai MY, Chen DS. Genotypes and clinical phenotypes of hepatitis B virus in patients with chronic hepatitis B virus infection. Journal of Clinical Microbiology 40: 1207-1209, 2002.

22. Karasawa T, Shirasawa T, Okawa Y, Kuramoto A, Shimada N, Aizawa Y, Zeniya M, Toda G. Association between frequency of amino acid changes in core region of hepatitis $B$ virus ( $\mathrm{HBV}$ ) and the presence of precore mutation in Japanese HBV carriers. Journal of Gastroenterology 32: 611-622, 1997.

23. Kaspar RT, Klein A, Aharonson S. Hepatits B virus precore mutants are identical in carriers from various ethnic origins and are associated with a range of disease severity. Hepatology 16: 1338-1342, 1992.

24. Kim WH, Kim KH, Chung JP, Kang JK, Park IS. Mutations in the pre-core region of hepatitis B virus DNA in patients with chronic liver diseases. Yonsei Medical Journal 34: 158-165, 1993.

25. Kwok R, Higuchi R. Avoiding false positives with PCR. Nature 339: 237 238, 1989.

26. Liaw YF, Tai DI, Chu CM, Lin DY, Sheen IS, Chen IJ, Pao CC. Early detection of hepatocellular carcinoma in patients with chronic B hepatitis. A prospective study. Gastroenterology 90: 263-267, 1986.

27. Lindh M, Andersson AS, Gusdal A. Genotypes, nt 1858 variants, and geographic origin of hepatitis B virus - large-scale analysis using a new genotyping method. Journal of Infectious Diseases 175: 1285-1293, 1997.

28. Lindh M, Hannoun C, Dhillon AP, Norkrans G, Horal G. Core promoter mutations and genotypes in relation to viral replication and liver damage in east asian hepatits B virus carriers. Journal of Infectious Diseases 179: 775-782, 1999.

29. Mangia A, Chung YH, Hoofnagle JH, Birkenmeyer L, Mushawar I, Di Bisceglie A. Pathogenesis of chronic liver disease in patients with chronic hepatits B virus infection without serum HBeAg. Digestive Diseases and Sciences 41: 2447-2452, 1996

30. Mbayed VA, Lopez JL, Telenta PFS, Palacios G, Badia I; Ferro A, Galoppo C, Campos R. Distribuition os hepatitis B virus genotypes in two different pedriatric populations from Argentina. Journal of Clinical Microbiology 36: 3362-3365, 1998.
31. Moraes MTB, Niel C, Gomes SA. A polymerase chain reaction-based assay to identify genotype $\mathrm{F}$ of hepatitis B virus. Brazilian Journal of Medical and Biological Research 32: 45-49, 1999.

32. Nitsuma H, Ishii M, Saito Y, Miura M, Kobayashi K, Ohori H, Toyoto T. Prevalence of precore defective mutant of hepatitis B virus in HBV carriers. Journal of Medical Virology 46: 397-402, 1995.

33. Norder H, Couroucé AM, Magnius LO. Complete genomes, phylogenetic relatedness, and structural proteins of six strains of hepatitis B virus, four of wich represent two new genotypes. Virology 198: 489-503, 1994.

34. Okamoto H, Tsuda F, Sakugawa H, Sastrosoewgnjo RI, Mitsunobu I, Miyakawa Y, Mayumi M. Typing hepatitis B virus by homology in nucleotide sequence: comparison of surface antigen subtypes. Journal General of Virology 69: 2575-2583, 1988

35. Okamoto H, Yotsumoto S, Akahane TY, Miyazaki Y, Sugai Y, Tsuda F, Tanaka T, Miyakawa Y, Mayumi M. Hepatitis B viruses with precore region defects prevail in persistently infect hosts along seroconversion to the antibody against e antigen. Journal of Virology 64: 1298-1303, 1990.

36. Raimondo G, Gianmichele M, Sardo MA, Rodino G, Salvatore C, Vecchi M, Pernice M, Rumi G, Tatarella M, Franchis R. Persistence of "wild-type" and "e-minus" hepatitis B virus infection in chronic healthy HBsAg/antiHBe positive carriers. Journal of Hepatology 20: 148-151, 1994.

37. Sanger, F, Nicklen S, Coulson AR. DNA sequencing chain-terminating inhibitors. Proceedings of the National Academy of Sciences of the United States of America 74: 54-63, 1997.

38. Santatonio T, Jung MC, Miska S, Pastore G, Pape GR, Will H. Prevalence and type of pre-C HBV mutants in anti-HBe positive carriers with chronic liver disease in highly endemic area. Virology 183: 840-844, 1991.

39. Sitnik R, Pinho JRR, Silva LC, Fonseca LEP, Carrilho FJ, Bernardini AP. Genótipos do vírus da hepatite B e mutações na região pré-core (VHB) em pacientes brasileiros com hepatite crônica B. In: Resumo na Gastroenterologia Endoscopia Digestiva 18 ( supl 1): S25, 1999.

40. Souto FJD. Distribuição da hepatite B no Brasil: atualização do mapa epidemiológico e proposições para seu controle. Gastroenterologia Endoscopia Digestiva 18: 143-150, 1999.

41. Stuyver L, Gendt S, Geyt CV, Zoulim F, Fried M, Schinazi R, Rossau R A new genotype of hepatitis B virus: complete genome and phylogenetic relatedness. Journal of General Virology 81: 67-74, 2000.

42. Takahashi K, Aoyama K, Ohno N, Iwata K, Akahane Y, Baba K, Yoshizawa H, Mishiro S. The precore/core promoter mutant (T1762/A1764) of hepatitis B virus: clinical significance and easy method for detection. Journal of General Virology 76: 3159-3164, 1995.

43. Takahashi K, Ohta Y, Kanai K, Akahane Y, Iwasa Y, Hino K, Ohno N, Yoshizawa $\mathrm{H}$, Mishiro S. Clinical implications of mutations C-to-T1653 and T-to-C/ A/ G1753 of hepatitis B virus genotype $\mathrm{C}$ in chronic liver disease. Archives of Virology 144: 1299-1308, 1999.

44. Thakur V, Guptan RC, Kazin SN, Malhotra V, Sarin SK Profile, spectrum and significance of HBV genotypes in chronic liver diseases patients in the Indian subcontinent. Journal of Gastroenterology and Hepatology 17: 165-170, 2002.

45. Tillmann H, Trautwein C, Walker D, Michitaka K, Böker K, Manns M. Clinical relevance of mutations in the precore genome of the hepatitis B virus. Gut 37: 568-573, 1995

46. Tu H, Xiong SD, Trepo C, Wen YM. Frequency of hepatitis B virus e-minus mutants varies among patients from different areas of China. Journal of Medical Virology 51: 85-89, 1997. 